\title{
THE EXISTENCE OF PEDESTRIAN IN JAKARTA
}

\author{
Riskha Mardiana1, R. Irawan Surasetja², Rr. Tjahyani Busono³, \\ Adi Ardiansyah ${ }^{4}$ \\ 1,2,3,4 Architecture, Universitas Pendidikan Indonesia, Bandung - Indonesia \\ JI. Dr. Setiabudhi No. 207, Bandung 40154, Indonesia
}

Corresponding Author: riskhamardiana@yahoo.com,
irawansurasetja@upi.edu,
tjahyanibusono@upi.edu,
ardiansyah.adi.jpta@gmail.com

$\begin{array}{cccr} & \text { Article History: } \\ \text { Received: } 28 \text { Februari } & \text { Revised: } 20 \text { Maret } & \text { Accepted: } 6 \text { April } & \text { Available online: 11 April } \\ 2019 & 2019 & 2019 & 2019\end{array}$

\begin{abstract}
Pedestrian is part of urban elements that have a significant role in forming a city. In the pedestrian, social interactions will be created which further strengthen relations between elements in the city. Cities in Europe are the best examples of city pedestrian planning. There walking is more comfortable and enjoyable, with the city being created by the streetscape and the humanist city order. Whereas in cities in developing countries like Jakarta, the city planning has not accommodated pedestrians at all.

The design of the city of Jakarta which is not humanist seems to urge pedestrians and force everyone to ride a car. The pedestrian paths provided are always side by side with the road and the volume is insufficient for those who pass it.

It can be concluded that the existing pedestrian conditions are unsafe and very uncomfortable. Examples of such cases can be seen along Jalan Sudirman and M.H. Thamrin which has always been the icon of the Jakarta office area. Where along these linear and continuous paths, pedestrians are forced to walk unprotected and face the pollution produced by vehicles. The lack of good pedestrian planning in this area has resulted in pedestrians preferring to use vehicles. Finally, each person is increasingly individualistic because there is no social interaction and the realization of a city that is not humanist too.
\end{abstract}

Keywords: Existance, Pendestrian, Jakarta, Urban Desain, Architecture

\section{Literature}

Circulation elements in design planning have an important role in urban structure. Circulation can form, direct, and control the pattern of activity. One of these circulation systems is a pedestrian path. According to Hamid Sirvani, pedestrians are an important element in urban planning and not just as a sweetener. Pedestrian is a comfort system that supports retail activities and serves to revive the vitality of city space. Good pedestrian planning will reduce people's dependence on vehicle use, especially in urban centers. By reducing the quantity of road vehicles, it will create an environment that is environmentally friendly and has a humanity scale.

According to (Charles Jencks, 1975 ) In the principle of designing pedestrians, things that must be considered are:

1. Optimal pedestrian volume, the width of the pedestrian should not be too large because it will seem arid and airy so people will be reluctant to go through it, nor should it be too narrow because it will be uncomfortable. The best is to repeat the module at least $1.2 \mathrm{~m}$ 
2. Security from

- Road, avoid crossing with road vehicles.

- Crime, complementing street lighting and social activities.

3. Convenience

- Physical, protected from the climate the distance must be adjusted to the ability of people to walk (300-400 m).

- Psychic, creating amenities and sequences so that people who cross it don't feel bored.

4. Clear and direct orientation

In pedestrian-pedestrian centers in the city, especially in commercial areas and services, it is important to pay attention to urban facilities from pedestrians and the balance between pedestrians and vehicle lanes. To provide facilities and revive the atmosphere of the pedestrian, Sirvany stressed that an interesting plot was needed, especially at street level. One way is to increase activity along the pedestrian, namely by creating shops, cafes. Another way that is also quite good is to provide activity support at certain points where people can stop to rest or at a pedestrian point where there are not many activities. Hamid Sirvani. The Urban Desig. (Jhon Wiley and Sons, 1994).

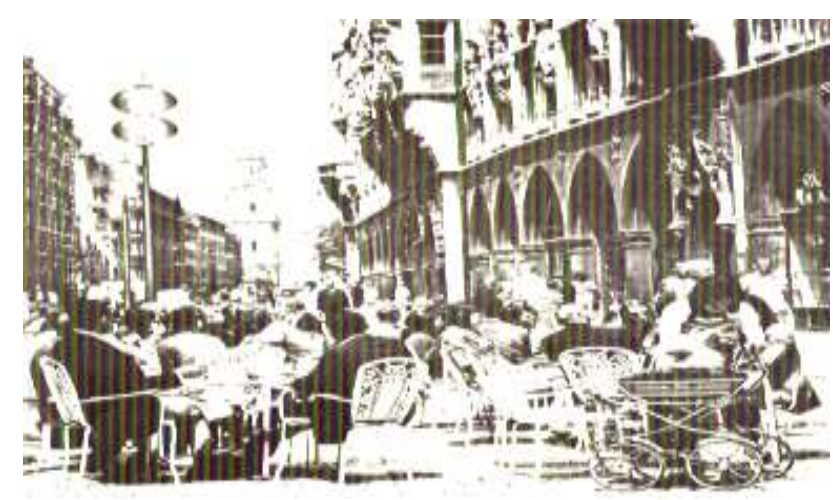

Figure 1. Hamid Sirvani, Pedestrian, 1985.

Activity support are all activities that help strengthen public spaces (one of which is pedestrian), because activities and physical space cannot be separated from one another. Integration and coordination between activity patterns is the most important part in planning supporting activitieas.

Now all cities in the western world are beginning to revise their urban planning for pedestrians, especially in shopping areas. The most minimal strategy is to improve the quality of existing pedestrian lines, by increasing the width and volume of the pedestrian, improving the landscape elements. Pedestrian has become more popular among the people and traders, where after there is a pedestrian their business increases to $40 \%$. Compared to the space needed by vehicles, the space needed by pedestrians is less and more optimal because it is used almost 24 hours. Based on (Ruben Stein and M. Harvey, 1992).

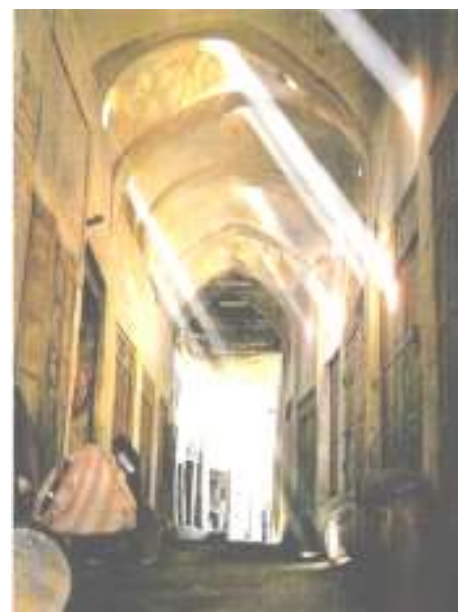

Figure 2. Image of City, Kevin Lynch, 1960 
In planning the pedestrian movement that must be considered is the type of movement, namely:

- $\quad$ Below the road level

- Appointed from the road level.

- Ground level or public street level, is the easiest and most commonly used system because the cost is cheaper and can be expanded according to the needs of its residents.

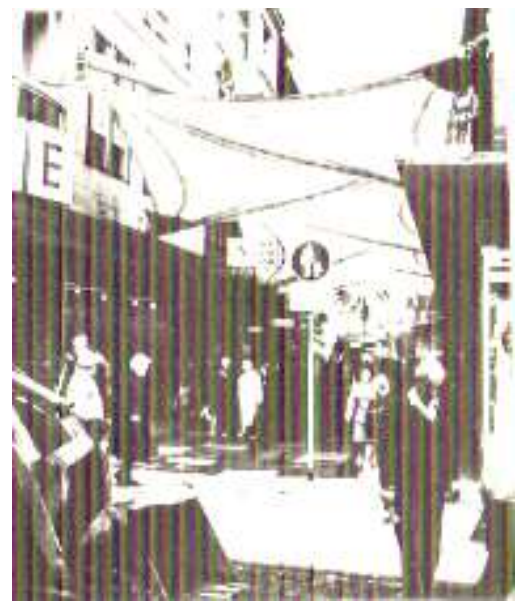

Figure 3. Brian Richard, Studio Vista, USA

One more thing that needs to be considered is how to control the climate in pedestrian lanes, especially those with tropical climates such as in Indonesia. The conventional way that can be applied is to provide a canopy in front of the building. In its development there were several pedestrian systems with arcades which were given roofs, even as in Japan there was a way of cooperation between buildings where the pedestrian was given a roof that was connected to the second floor of each building.

Pedestrian systems that move above or above the ground at the same time are being developed and have long-term targets. And in cities that have a traffic system that is used is the surface level of the land. Next is Richard declare in a city or city pedestrian system where there is a combination of the 3 migration systems. This is done to break down the static circulation that is continuous and boring.(Brian Richard, Moving to City, 1976, Studio Vista, USA)

Good pedestrians are busy pedestrians and through social activities. To give birth to positive conditions 3 basic principles are needed:

1. Optimal density

The full road corridor becomes bigger as a pedestrian generator which gives rise to lively social activity

2. Supporting land use

The function of land that supports the public such as jeans and trade can help activate pedestrian public activities

3. Corridors of roads that are well designed and meticulous

4. (M.Ridwan Kamil, Forgotten Space: The Phenomenon of Road Corridors that Are Reverse As City Public Spaces, 2004, Infourdi, Jakarta.

\section{Discussion and Results}

Discussion (Case Study: Pedestrian Along Jalan Sudirman and Jalan M.H. Thamrin)

The problem faced by urban planners in Indonesia's big cities like in Jakarta is the lack of attention to pedestrians. Pedestrian theory has an important role in reviving a region. While the circulation system in Jakarta is more concerned with the interests of private vehicles than public vehicles and especially pedestrians. Observing the existing transportation system in Jakarta is mostly a combination of pedestrians, slow lanes, fast lanes and bus lanes, which seem to be mixed and the settings are unclear. With the joining of the three circulations, pedestrians were forced to walk combing the highway with a narrow volume so that it was uncomfortable and certainly not safe.

Pedestrian paths along the Sudirman roadside and M.H. road Thamrin showed these symptoms. This pedestrian adopts a ground level movement system whose purpose is to connect the building to the next building. Since 2003, the DKI Jakarta government has been pursuing a 
pedestrianization program by renovating track materials from paving blocks to concrete, this has created enough comfort for people who walk, especially women. The addition of physical elements such as street lights and signage is enough to provide identity and orientation. Based on the theory should be in the service and commercial areas such as in the Sudirman-Thamrin area, the pedestrian will create an intensity of social activity, so the vitality of the pedestrian is quite high. But unfortunately there are other considerations that are not considered in the initial design of the pedestrian, so that it does not seem to function as it should.

Pedestrian in this area is felt to be less alive due to the absence of social activities which become an additional problem. This is due to the fact that there is a miscalculation of the design and quality of the pedestrian, there are architectural aspects that are often found everyday which are generally anti-urban and do not create social activities. The design problems that exist in pedestrians along Sudirman-Thamrin are:

1. The pedestrian lane in the Sudirman-Thamrin area is still psychologically not yet comfortable because it is very arid and too long. Along the route also does not have streetscapes except the massive glass walls of office buildings. Stop points are only stops and nodes such as clover bridges and $\mathrm{HI}$ roundabouts that cannot be traversed.

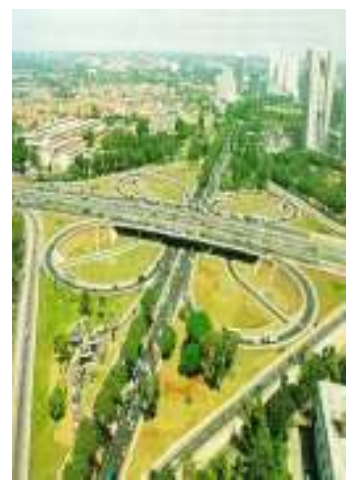

node located at the clover roundabout, pedestrians do not have a clear orientation to continue the journey
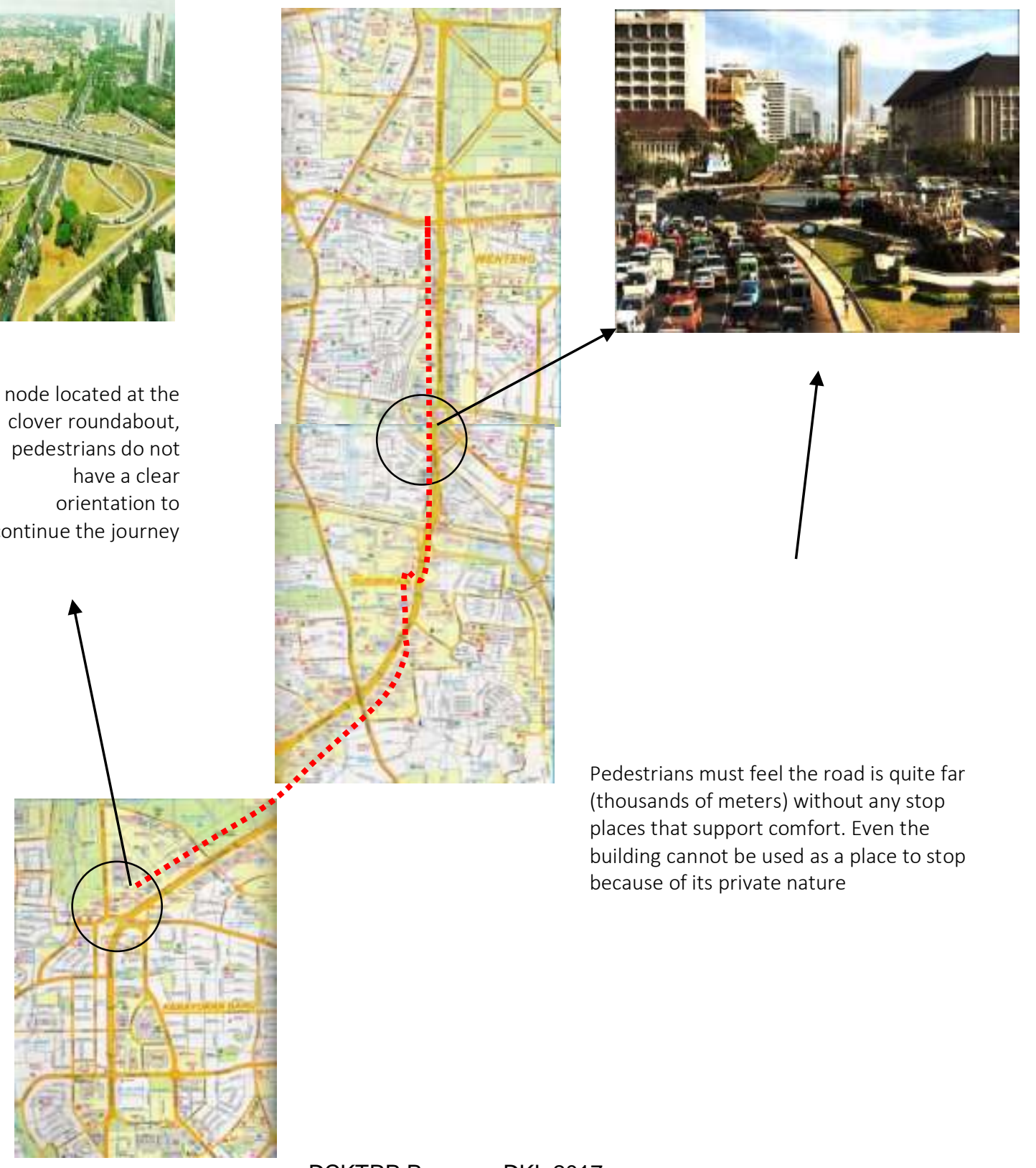


\section{Bolders}

Conceptually the birth of border line regulations is to ensure there is sufficient distance between the public space to the private space (building). Initially this concept was aimed at residential or government buildings that needed high privatization. Finally, all buildings and even offices and commercial areas in this protocol also adopted the same building typology. As a result of buildings being alienated from their urban areas, there is no spatial interaction between architecture and city residents as a choice for relaxing activities in an urban context.

3. The 'drop-off' concept that is now also applied to every building typology

Forcing a drop-off in each lobby of a building whether or not canopy, is initially intended for hotel typologies where guests generally do not carry vehicles. Because of the increasingly lazy mentalism of city dwellers, this typology develops. Whereas in advanced cities the concept is rarely used.

4. The absence of urban linkage

Planning functions at street level in this area are generally not public so that between buildings with each other and with pedestrians are separated. This resulted in the death of urban corridor activities in the afternoon and at night. The presence of essential public functions such as restaurants and cafes generally occupies the upper floors or behind buildings which are clearly not directly related to public spaces or road corridors. Even for commercial areas such as the Ratu Plasa Shopping Center, they still do not feel related to pedestrians.

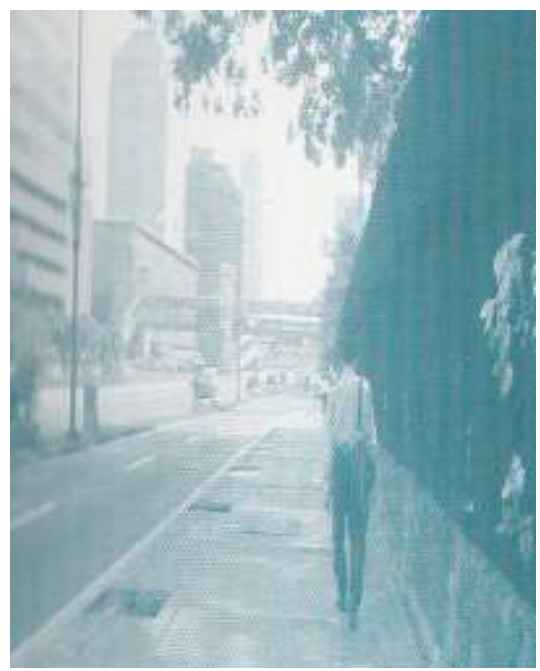

Figure 5. Disconnection of public space relations with buildings due to fences Source: Riskha Mardiana,2018

The Plaza still does not feel associated with pedestrians because it is limited by a fence.

5. Pedestrians do not pay attention to tropical urban elements

As one of the elements of a tropical city, these pedestrians did not adopt the rules of tropical architecture. Pedestrians are not protected by natural or artificial shade, especially afterwards the pedestrian around the road was renovated with concrete

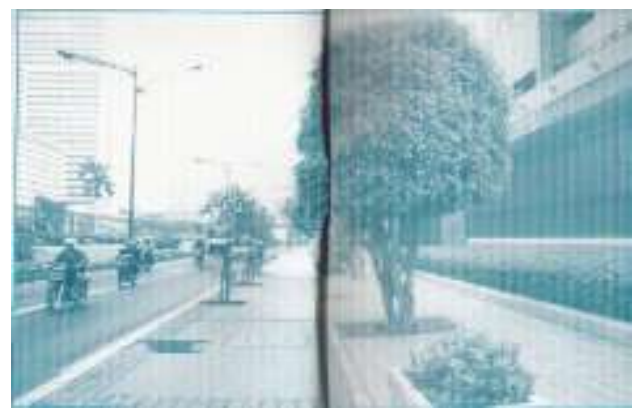

Figure 6. Conditions before pedestrians were approved, now more arid Source: Riskha Mardiana, 2018 
RESULT

A good pedestrian is a pedestrian who can live the activities of the city and there is intensive social activity in it. So to anticipate these problems there needs to be a revitalization of pedestrians by applying the design rules as follows:

1. To break the distance that is too far away, it must be made nodes and discharge points given the activity support so that the pedestrian becomes more alive and comfortably psychologically.

2. Collaborating with building owners to open fence boundaries and make the building's back area become a public area, so that previously narrow pedestrians become bigger and more physically comfortable and between buildings dynamic relationships are established.

3. Creating urban-linkage by putting public functions on street level, such as putting down retail and restaurants / cafes on the first floor so pedestrians can enjoy street window shopping and pedestrian life.

4. Make linkages between buildings both by way of ground level, namely by removing the fence boundary between buildings. You can also use a pedestrian that is lifted from the road level. The pedestrian connects the upper floor which is still classified as public.

5. Pedestrian lanes along the Sudirman-Thamrin road must be sheltered so that pedestrians walking along can be more comfortable, protected from rain and heat. Because the road conditions do not make it possible to make arcades and canopies that are needed quite large, the least effort and the easiest is to plant lush plants like in Singapore. Thus the face of the city will feel more beautiful.

\section{Conclusion}

Pedestrian is an element that supports humanity in shaping the city. With the city pedestrian will feel more human. In designing pedestrians the most important is the factor of safety and comfort. Apart from that technical factors such as capacity, orientation and maintenance are also important. The movement system determines what type of pedestrian we can use.

For tropical cities like in Jakarta, climate factors take part because with the intensity of the sun the high pedestrian paths must be designed with shade. Unfortunately, pedestrian planning on the streets such as along Sudirman-Thamrin has not yet addressed the pedestrian problem. As a result, each individual even more isolated buildings due to the absence of social interaction.

For this reason, there needs to be an effort to revive pedestrians in this region by giving injections of supporting activities and creating relationships between buildings and buildings with pedestrians. By providing lush trees along the pedestrian can protect pedestrians from the climate so that the achievement of physical and psychological comfort. All of these efforts aimed at reviving the pedestrian atmosphere on Jalan Sudirman - Thamrin so that people would prefer to walk rather than use vehicles. And finally the volume of vehicles has diminished and the city will feel more human.

\section{Reference}

Brian Richard. (1976). Moving to City. Studio Vista, USA)

Jencks, Charles. (1973). Modern Movements in Architecture. Anchor Press.

Lynch, Kevin. (1960). The Image Of The City. MIT Press.

Wiley, Jhon and Sons. (1994). Urban Design: The American Experience. Canada: Published Simultaneously.

Rubenstein, M. Harvey. (1992). Pendestrian Malls, Streetscapes, and Urban Spaces. Canada: Published Simultaneously. 